\title{
Nonsyndromic Oral Clefts and COVID-19 Crisis: Some Considerations on the Delay in Clinical Management of Patients
}

\author{
Hercílio Martelli-Júnior ${ }^{1,2}$, Renato Assis Machado ${ }^{3,4} @$, Daniella R. Barbosa Martelli¹, Ricardo Della \\ Coletta $^{3}$, Mário Sérgio Oliveira Swerts ${ }^{2}$
}

'Oral Diagnosis, Dental School, State University of Montes Claros, Montes Claros, MG, Brazil.

${ }^{2}$ Center for Rehabilitation of Craniofacial Anomalies, Dental School, University of Alfenas, MG, Brazil.

${ }^{s}$ Department of Oral Diagnosis, Dental School, University of Campinas, Piracicaba, SP, Brazil.

${ }^{4}$ Hospital for Rehabilitation of Craniofacial Anomalies, University of São Paulo, Bauru, SP, Brazil.

\section{Corresponding author:}

Renato Assis Machado - ORCID: 0000-0002-1697-3662

E-mail: renatoassismachado@yahoo.com.br.

Received: 07 July 2020 / Accepted: 23 July 2020 / Published: 17 August 2020

Dear Editor,

In 2020, when we searched the word "Coronavirus" in PubMed, 19,085 papers were found, a daily average of 100.9 papers/day. These papers discussed several aspects of COVID-19 pandemic, including signals and symptoms, spread of virus, risk of health workers, drugs and treatment (https://www.ncbi.nlm.nih.gov/pubmed/). The scientific literature related to dentistry is still limited, with studies exploring areas of clinical care [1-5], immunobiology of oral mucosa [6], and the use of social media and telemedicine [7]. However, no reports on impact of treatment and management of patients with oral clefts have yet been described.

Nonsyndromic oral clefts (NOC) are amongst the most prevalent congenital abnormalities in humans (approximately 1 in 700 live births), and are considered important public health problem mainly due to the high risk of mortality, reaching up to $30 \%$ in underdeveloped countries and in specific areas in developed countries, and significant morbidities [8]. Both esthetic consequences and functional impairment, such as restriction of maxillofacial growth, dental changes, speech and chewing disorders and hearing problems, affect patients' health and quality of life and demand longstanding treatment, in some cases for the entire life of patient [9].

As a result, the patients with NOC require specialized treatment, follow-up and comprehensive longterm assistance in highly complex reference centers. The treatment of NOC should be instituted soon after birth, aiming a global treatment in the morphological, functional and psychosocial rehabilitation. It should be started with reparative plastic surgery - cheiloplasty (lip surgery at three months) and palatoplasty (around 1 year of age), when indicated. Afterwards, the patients are monitored throughout their growth when they will 
receive interdisciplinary assistance. Secondary surgeries, columella stretching or even pharyngoplasty, are performed from the age of $2-5$ years $[10,11]$. At 5 years of age, the refinement of nose surgery is expected in $35 \%$ of cases. Orthognathic surgery is performed in $20 \%$ of cases, but only after the patient's growth [10,11]. Between the surgeries, patients are assisted by speech therapists, psychologists, dentists and other health workers. Therefore, the treatment of a patient with NOC extends for decades and complete rehabilitation will only be possible if the patient is always present in the reevaluations by the multidisciplinary team [12].

Analyzing the projections of COVID-19 transmission, in the absence of an effective preventive measure, there will possibly be a need for intermittent or prolonged isolation and social distancing measures until 2022. Even in periods of apparent control of pandemic, surveillance must be maintained, as the risk of a resurgence of new waves of spread and contamination may be possible until 2024 [13]. At this time that many specialized Centers and Hospital are closed or with various clinical limitations of operation, especially in elective and non-emergency procedures, it is necessary and important to think in alternatives to at least minimize the problems arising from the thousands of children who are being born in this period of global quarantine with NOC.

Members of international and national associations (Speech Therapists, Plastic Surgeons, Physiotherapists, Psychologists, Oral and Maxillofacial Surgery, Head and Neck Surgery and Otorhinolaryngology) and Dental and Medical Schools around the world could mobilize themselves to produce quality online content on Websites, Instagram, YouTube, and other apps that allow the transmission of videos and lives, and guidelines for the families of patients with NOC. Individual specialists are also encouraged for such action, as such direct individual communication with the patients and their families. In addition, when possible, a rapid and organized return of services will be required for reception and rehabilitation in patients with NOC as well as the guidelines for their families.

\section{References}

[1] De Felice F, Polimeni A, Valentini V. The impact of Coronavirus (COVID-19) on head and neck cancer patients' care. Radiother Oncol 2020; 147:84-5. https://doi.org/10.1016/j.radonc.2020.03.020

[2] Ellis R, Hay-David AGC, Brennan PA. Operating during the COVID-19 pandemic: How to reduce medical error. Br J Oral Maxillofac Surg 2020; 58(5):577-80. https://doi.org/10.1016/j.bjoms.2020.04.002

[3] Mallineni SK, Innes NP, Raggio DP, Araujo MP, Robertson MD, Jayaraman J. Coronavirus disease (COVID-19): Characteristics in children and considerations for dentists providing their care. Int J Paediatr Dent 2020; 30(3):24550. https://doi.org/10.1111/ipd.12653

[4] Meng L, Hua F, Bian Z. Coronavirus Disease 2019 (COVID-19): Emerging and future challenges for dental and oral medicine. J Dent Res 2020; 99(5):481-7. https://doi.org/10.1177/0022034520914246

[5] Prati C, Pelliccioni GA, Sambri V, Chersoni S, Gandolfi MG. COVID-19: its impact on dental schools in Italy, clinical problems in endodontic therapy and general considerations. Int Endod J 2020; 53(5):723-5. https://doi.org/10.1111/iej.13291

[6] Peng X, Xu X, Li Y, Cheng L, Zhou X, Ren B. Transmission routes of 2019-nCoV and controls in dental practice. Int J Oral Sci 2020; 12(1):9. https://doi.org/10.1038/s41368-020-0075-9

[7] Machado RA, de Souza NL, Oliveira RM, Martelli Júnior H, Bonan PRF. Social media and telemedicine for oral diagnosis and counselling in the COVID-19 era. Oral Oncol 2020; 105:104685. https://doi.org/10.1016/j.oraloncology.2020.104685

[8] Wehby GL, Castilla EE, Goco N, Rittler M, Cosentino V, Javois L, et al. The effect of systematic pediatric care on neonatal mortality and hospitalizations of infants born with oral clefts. BMC Pediatr 2011; 11:121. https://doi.org/10.1186/1471-2431-11-121

[9] Nolte FM, Bos A, Prahl C. Quality of life among Dutch children with a cleft lip and/or cleft palate: a follow-up study. Cleft Palate Craniofac J 2019; 56(8):1065-71. https://doi.org/10.1177/1055665619840220

[10] Salyer KE. Excellence in cleft lip and palate treatment. J Craniofac Surg 2001; 12(1):2-5. https://doi.org/10.1097/00001665-200101000-00002 
[11] Santos CF, Garlet GP. The experience and excellence of the Hospital for Rehabilitation of Craniofacial Anomalies, University of São Paulo (HRAC/USP), in the rehabilitative treatment of cleft lip and palate. J Appl Oral Sci 2013; 21(6):496. https://doi.org/10.1590/1678-77572013edoo6

[12] Franco D, Gonçalves LF, Franco T. Management of cleft lip and palate in Brazil. Scand J Plast Reconstr Surg Hand Surg 2003; 37(5):272-6. https://doi.org/10.1080/02844310310002949

[13] Kissler SM, Tedijanto C, Goldstein E, Grad YH, Lipsitch M. Projecting the transmission dynamics of SARS-CoV-2 through the postpandemic period. Science 2020; 368(6493):860-8. https://doi.org/10.1126/science.abb5793 